\title{
Mitochondrial function and critical temperature in the Antarctic bivalve, Laternula elliptica
}

\author{
Hans O. Pörtner ${ }^{\mathrm{a}, *}$, Iris Hardewig ${ }^{\mathrm{a}}$, Lloyd S. Peck ${ }^{\mathrm{b}}$ \\ a Alfred-Wegener-Institut für Polar- und Meeresforschung, Biologie I/Ökophysiologie, Postfach 1201 61, D-27515 Bremerhaven, Germany \\ ${ }^{\mathrm{b}}$ British Antarctic Survey, High Cross, Madingley Road, Cambridge CB3 OET, UK
}

Received 6 May 1999; received in revised form 26 July 1999; accepted 3 August 1999

\begin{abstract}
Thermal sensitivities of maximum respiration and proton leakage were compared in gill mitochondria of the Antarctic bivalve Laternula elliptica for an assessment of the contribution of mitochondrial mechanisms to limiting temperature tolerance. Proton leakage was measured as the oxygen consumption rate during blockage of oxidative phosphorylation (state IV respiration + oligomycin). The maximum capacity of NADP dependent mitochondrial isocitrate dehydrogenase (IDH) was investigated as part of a proposed mitochondrial substrate cycle provoking proton leakage by the action of transhydrogenase. State III and IV + respiration rose exponentially with temperature. Thermal sensitivities of proton leakage and IDH were unusually high, in accordance with the hypothesis that $\mathrm{H}^{+}$leakage is an enzyme catalysed process with IDH being involved. In contrast to proton leakage, state III respiration exhibited an Arrhenius break temperature at $9^{\circ} \mathrm{C}$, visible as a drop in thermal sensitivity close to, but still above the critical temperature of the species $\left(3-6^{\circ} \mathrm{C}\right)$. Progressive uncoupling of mitochondria led to a drop in RCR values and $\mathrm{P} / \mathrm{O}$ ratios at high temperature. The same discontinuity as for state III respiration was found for the activity of mitochondrial IDH suggesting that this enzyme may influence the thermal control of mitochondrial respiration. In general, the high thermal sensitivity of proton leakage may cause an excessive rise in mitochondrial oxygen demand and a decreased efficiency of oxidative phosphorylation. This may exceed the whole animal capacity of oxygen uptake and distribution by ventilation and circulation and set a thermal limit, characterized by the transition to anaerobic metabolism. (C) 1999 Elsevier Science Inc. All rights reserved.
\end{abstract}

Keywords: Activation energy; Antarctic bivalve; Cold adaptation; Critical temperature; Isocitrate dehydrogenase; Laternula elliptica; Mitochondria; Proton leak

\section{Introduction}

Critical temperature thresholds $\left(T_{\mathrm{c}}\right)$ have been defined for various marine invertebrate species and fish as being characterized by the transition to an anaerobic mode of metabolism, once temperature reaches low or high extremes ([44,47,53]; for review see [38,39]). A unidirectional shift of both $T_{\mathrm{c}}$ values occurs with latitude and seasonal temperature adaptation. These thresholds characterize the geographical distribution of a species. The within species comparison of temperate and subpolar populations suggests that a shift in both low and high $T_{\mathrm{c}}$ is associated with a change in mito-

\footnotetext{
* Corresponding author. Tel.: + 49-471-4831-307; fax: +49-4714831-149.

E-mail address: hpoertner@awi-bremerhaven.de (H.O. Pörtner)
}

chondrial density, which drops as the temperature rises and increases as the ambient temperature falls [45]. This finding strongly suggests that the $T_{\mathrm{c}}$ values are set by a mismatch of mitochondrial oxygen supply and demand $[38,39]$.

A special situation may have developed in polar areas, especially the Antarctic where the marine fauna is constantly exposed to low temperatures between 1.9 and $+1{ }^{\circ} \mathrm{C}$. Considering that life in warm waters reflects the likely original evolutionary situation [2] organisms inhabiting Antarctic oceans must have developed special physiological adaptations to overcome the adverse effects of cold temperatures on metabolism. In Antarctic fish a compensatory increase in whole animal aerobic capacity is reflected in higher mitochondrial densities [18] and the 1.5-5-fold rise in the capacity of 
some oxidative enzymes [14] despite low resting metabolic rates [13]. Compared to temperate species the drop in the low $T_{\mathrm{c}}$ to below polar temperatures on evolutionary time scales is also linked to a drop in the upper $T_{\mathrm{c}}$ and a narrowing of the tolerated temperature window $[38,39]$.

In conclusion, mitochondrial performance is a characteristic element in adaptation to temperature and its limitations. The question arises which features of mitochondrial function determine the low and the high $T_{\mathrm{c}}$. Failure of oxidative enzymes has been discussed to limit resistance to high temperatures [36]. According to a previous hypothesis the falling rates of oxygen consumption below a low $T_{\mathrm{c}}$ reflect insufficient aerobic capacity unable to meet energy requirements [53], whereas beyond a high critical temperature mitochondrial oxygen demand may become excessive and may no longer be met by oxygen supply via ventilation and circulation $[38,39]$. It is important in this context that mitochondrial oxygen demand is not only defined by the rate of ADP phosphorylation depending on energy demand but also by the rate of proton leakage which covers a significant fraction of standard metabolic rate (SMR) [5]. Proton leakage and the associated metabolic activity can be interpreted to reflect part of the cost of mitochondrial maintenance $[38,39]$.

As part of a larger effort to address the effect of temperature on mitochondrial functions in fish and marine invertebrates this study was designed to investigate mitochondrial respiration in gill mitochondria of a stenothermal Antarctic organism, the benthic infauna bivalve Laternula elliptica. L. elliptica is a widely distributed, large Antarctic bivalve burrowing up to $50 \mathrm{~cm}$ deep in soft, muddy sediments [24]. It occupies a similar ecological niche as the genus Mya in the northern hemisphere [40].

Temperature effects on oxygen consumption and on the efficiency of coupling electron transport to ATP production were studied in order to determine when high temperatures possibly disrupt mitochondrial function. Mitochondrial NADP dependent isocitrate dehydrogenase was included in this investigation. Study of this enzyme was particularly promising since its isozyme pattern changed in the body wall of Arenicola marina in a latitudinal gradient and was linearly correlated with mean ambient temperature [27]. Recently, this enzyme was suggested to adopt a key role in a mitochondrial substrate cycle which is likely to be relevant in the control of mitochondrial respiration and proton leakage $[39,42]$. In parallel experiments the $T_{\mathrm{c}}$ of $L$. elliptica was determined to lie between 3 and $6^{\circ} \mathrm{C}$ as indicated by the onset of anaerobic metabolism (Pörtner et al., in preparation).

\section{Material and methods}

\subsection{Animals}

Antarctic clams, Laternula elliptica, were collected by scuba diving on the North side of Rothera point, Adelaide Island, Antarctica (67 34'S, $\left.6807^{\prime} \mathrm{W}\right)$, at a depth of $25-33 \mathrm{~m}$ in December 1997. A total of 22 clams with a mean tissue wet weight of $60.1 \pm 13.4 \mathrm{~g}$ (equivalent to $113.1 \mathrm{~g}$ whole animal wet weight) were kept in aquaria with continously running seawater at ambient temperature for at least 1 week prior to experimentation. Experiments were conducted at Rothera Station (British Antarctic Survey, Antarctica).

\subsection{Preparation of mitochondria}

Large clams were removed from the aquaria and opened by cutting the adductor muscle and mantle edge. Approximately $2-3 \mathrm{~g}$ of gill tissue were quickly removed and chopped finely by using scissors in a petri dish containing 3-4 $\mathrm{ml}$ of ice-cold isolation buffer modified after Moyes et al. [33]: $70 \mathrm{mM}$ Hepes; 100 $\mathrm{mM} \mathrm{KCl}, 400 \mathrm{mM}$ sucrose, $3 \mathrm{mM}$ EDTA, $6 \mathrm{mM}$ EGTA, $1 \% \mathrm{BSA}, 1 \mu \mathrm{g} \mathrm{ml}^{-1}$ aprotinin, $\mathrm{pH} 7.3$ at $20^{\circ} \mathrm{C}$ ). Extraction occurred in $30 \mathrm{ml}$ of the same buffer by use of a Potter-Elvejhem homogenizer. The tissue was dispersed by three passes of a loosely fitting pestle. After centrifugation $(10 \mathrm{~min}$ at $1250 \times \mathrm{g})$ the pellet was rehomogenized in $30 \mathrm{ml}$ of isolation buffer and centrifuged again. The combined supernatants were spun at $10500 \times g$ for $10 \mathrm{~min}$. The mitochondrial pellet was resuspended in $2-2.5 \mathrm{ml}$ of assay medium $(70 \mathrm{mM}$ Hepes, $100 \mathrm{mM} \mathrm{KCl}, 560 \mathrm{mM}$ sucrose, $10 \mathrm{mM}$ $\mathrm{KH}_{2} \mathrm{PO}_{4}, 1 \mu \mathrm{g} \mathrm{ml}{ }^{-1}$ aprotinin, $5 \mathrm{mM}$ glutamate, $\mathrm{pH}$ 7.3 at $20^{\circ} \mathrm{C}$ ) with $1 \%$ BSA yielding $11-17 \mathrm{mg}$ mitochondrial protein $\mathrm{ml}^{-1} . \Delta \mathrm{pH} / \Delta T$ of the assay medium was -0.014 units ${ }^{\circ} \mathrm{C}^{-1}$. Mitochondrial preparations remained stable for at least $8 \mathrm{~h}$, as verified by repeated analysis of respiratory performance at $0^{\circ} \mathrm{C}$.

\subsection{Mitochondrial respiration}

Oxygen consumption was measured at different temperatures using a Clarke-type oxygen electrode in a thermostatted respiration chamber (Eschweiler, Kiel). A total of 100 (sometimes 200) $\mu$ l of the mitochondrial suspension were combined with assay medium to a total volume of $1 \mathrm{ml}$ containing 1.1-1.7 (sometimes 2.2-3.4) $\mathrm{mg}$ mitochondrial protein $\mathrm{ml}^{-1}, 5 \mu \mathrm{M}$ diadenosine pentaphosphate $\left(\mathrm{AP}_{5} \mathrm{~A}\right)$, an inhibitor of myokinase as well as $20 \mathrm{mM}$ glutamate and $0.1 \mathrm{mM}$ pyruvate as substrates [32]. State III respiration was recorded after the addition of ADP to a level of 0.3 $\mathrm{mM}$. After all ADP had been phosphorylated state IV respiration was determined. Finally, the respiration rate 
induced by proton leakage was recorded after adding oligomycin, an inhibitor of mitochondrial $\mathrm{F}_{0} \mathrm{~F}_{1}$-ATP synthase, to a concentration of $2.8 \mu \mathrm{g} \mathrm{ml}^{-1}$. Repeated addition of oligomycin verified the suitability of this concentration for a maximum effect. Respiration under oligomycin remained constant for a minimum period of 15 min before it tended to rise, possibly caused by a progressive increase in membrane potential during inhibition of the ATP synthase (see below).

For comparison with the classical $\mathrm{P} / \mathrm{O}$ ratios determined according to Chance and Williams [12] effective $\mathrm{P} / \mathrm{O}$ ratios of oxidative phosphorylation were analysed by direct investigation of ATP production during state III respiration. Samples of $10 \mu \mathrm{l}$ assay medium were repeatedly withdrawn from the respiration chamber after the onset of state III respiration and then after $\mathrm{P}_{\mathrm{O}_{2}}$ decrements of at least $10 \mathrm{~mm} \mathrm{Hg}$. Samples were diluted in $990 \mu \mathrm{l}$ of buffer solution $(0.2 \mathrm{M}$ Tris-acetate $\mathrm{pH}$ $7.75,1 \mathrm{mM}$ EDTA) and heated briefly to $95^{\circ} \mathrm{C}$ in a water bath for the denaturation of mitochondria. ATP concentrations were determined luminometrically with an ATP assay kit (BioOrbit, Finland) following the rationale of Wibom et al. [50]. Effective $\mathrm{P} / \mathrm{O}$ ratios were calculated as ATP production rates divided by the rate of oxygen consumption monitored in the same assay.

For the analysis of a potential oxygen dependence of $\mathrm{P} / \mathrm{O}$ ratios respiration was started by the addition of ADP to levels in the assay ranging up to $0.9 \mathrm{mM}$. ATP samples were withdrawn repeatedly over the time course of the experiment until state IV respiration was reached. Spontaneous ATP depletion and a potential involvement of an ATPase in this process [31] were investigated by monitoring ATP levels during state IV respiration. After ATP levels had been demonstrated to remain more or less constant, antimycin $(5 \mu \mathrm{M}$ for an inhibition close to complex II of the respiratory chain), rotenone $(8 \mu \mathrm{M}$ for an inhibition of complex I) and sodium azide $(2 \mathrm{mM})$ were added prior to or after the addition of oligomycin. These analyses were carried out at $3^{\circ} \mathrm{C}$ when the sensitivity of mitochondrial assays was improved over the measurement at $0^{\circ} \mathrm{C}$ and the quality of mitochondria not yet compromised by temperature effects.

Oxygen solubility in the assay medium at different temperatures was taken from Johnston et al. [28]. Protein concentration of the mitochondrial pellet was determined by the Biuret method, after adding 5\% deoxycholate to the mitochondrial suspension for the solubilization of membrane proteins.

\subsection{Enzyme assay}

$\mathrm{NADP}^{+}$-dependent isocitrate dehydrogenase activity was analysed in isolated mitochondria after their lysation by the addition of $5 \%$ deoxycholate. The assay contained $70 \mathrm{mM}$ Tris- $\mathrm{HCl} \mathrm{pH} 7.1,8 \mathrm{mM} \mathrm{MgSO}_{4}, 2.5$
$\mathrm{mM} \mathrm{NADP}{ }^{+}, 1 \mathrm{mM} \mathrm{MnCl}, 3 \mathrm{mM} \mathrm{D} / \mathrm{L}$-isocitrate and $20 \mathrm{mM}$ citrate (modified after Alp et al. [1]). Enzyme activity was measured following the appearance of NADPH at $339 \mathrm{~nm}$ in a thermostatted spectrophotometer at $0,3,4.5,9,15,21,25$ and $30^{\circ} \mathrm{C}$. The temperature range chosen and variations in substrate levels ensured that the enzyme always operated at saturating substrate levels. This was confirmed by the extreme rise in enzyme activity with temperature which would be prevented by substrate limitations.

\subsection{Calculation of ABTs and statistical analyses}

All values are given as means \pm SD unless indicated otherwise, $N=7$ for mitochondrial respiration experiments and $N=4$ for enzyme activities. Data were plotted as a function of temperature. ABTs were calculated by applying two-phase regressions, which compared sequential linear or 2 nd order polynomial fits. Two intersecting lines were selected that fitted the data best according to the method of least squares following the rationale of Yeager and Ultsch [35,48]. Differences between rates in respiratory states III, IV and IV + oligomycin were tested for significance by Student's $t$-test for paired samples. Statistical significance of changes in RCR, Arrhenius activation energy, $Q_{10}$ values, $\mathrm{P} / \mathrm{O}$ ratios and ATP degradation with temperature or time was evaluated at the $P \leq 0.05$ level using analysis of variance (ANOVA) and of covariance (ANCOVA) performing contrasts for means comparisons (Super-Anova and StatView II, Abacus Concepts).

\section{Results}

\subsection{Quantification of mitochondrial functions}

Gill mitochondria of L. elliptica were highly coupled at $0^{\circ} \mathrm{C}$ with a respiratory control ratio $(\mathrm{RCR}+)$ of $5.74 \pm 1.36$ (Fig. 1). This $\mathrm{RCR}+$ ratio was calculated as the ratio of state III and state IV respiration under oligomycin (state IV + ). With a value of $3.78 \pm 1.60$ the traditional RCR was only slightly lower and within the range of RCR values reported for other bivalve gill mitochondria [3,10,11]. RCR remained more or less constant between 0 and $9^{\circ} \mathrm{C}$ and fell progressively and significantly at higher temperatures. Maximal oxidative capacity in the presence of glutamate and pyruvate was $2.12 \pm 0.67 \mathrm{nmol} \mathrm{O} \mathrm{min}^{-1} \mathrm{mg}^{-1}$ mitochondrial protein at $0^{\circ} \mathrm{C}$.

Residual respiration under oligomycin is assumed to quantify oxygen consumption due to proton leakage through the inner mitochondrial membrane. Leakage reached a rate equivalent to $18.1 \pm 3.7 \%$ of state III respiration at $0^{\circ} \mathrm{C}$ (Fig. 1), evaluated from an initially stable reading before state IV + respiration started to 
rise 10-15 min after the addition of oligomycin (not shown). Owing to its dependence on proton motive force, the actual percent fraction of proton leakage in phosphorylating state III mitochondria will be lower since proton motive force in state III is below the one under state IV conditions (see Section 4).

Spontaneous ATP depletion was small and non-significant under the effect of oligomycin, even at high phosphorylation potential (Fig. 2A). It occurred at a somewhat, but not significantly larger rate when antimycin, rotenone and sodium azide were added after oligomycin (Fig. 2A). Significant ATP depletion under antimycin, rotenone and sodium azide was not eliminated when oligomycin was added (Fig. 2B) reflecting a more complete inhibition of ATP synthesis by the other inhibitors than with oligomycin alone.
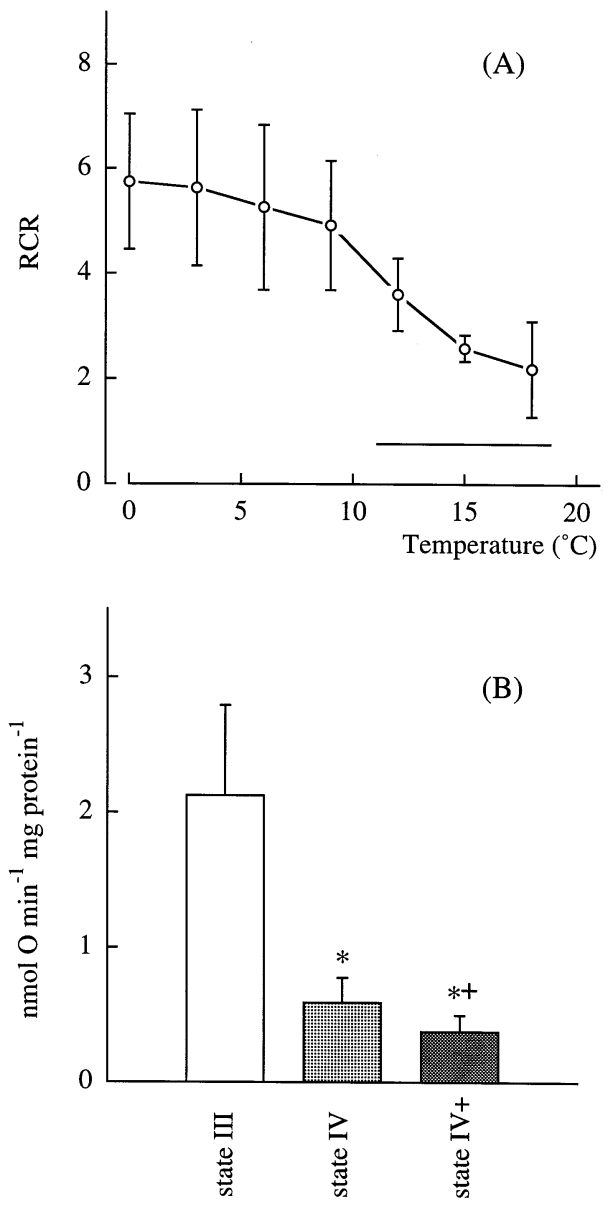

Fig. 1. (A) Respiratory coupling ratios determined from state III respiration and respiration under oligomycin $(\mathrm{RCR}+)$ of isolated $L$. elliptica gill mitochondria. A horizontal line indicates onset and maintenance of a significant difference from RCR values at lower temperatures. (B) Rates of state III and state IV respiration of gill mitochondria from L. elliptica at $0^{\circ} \mathrm{C}$ compared to state IV respiration under oligomycin (state IV +). State IV + respiration is suggested to largely comprise proton leakage. Mitochondria respired on $20 \mathrm{mM}$ glutamate and $0.1 \mathrm{mM}$ pyruvate as substrates. ${ }^{*}+$, indicate significant differences of respiratory rates from the rate observed under state III $(*)$ as well as from the rate under state IV $(+)$.
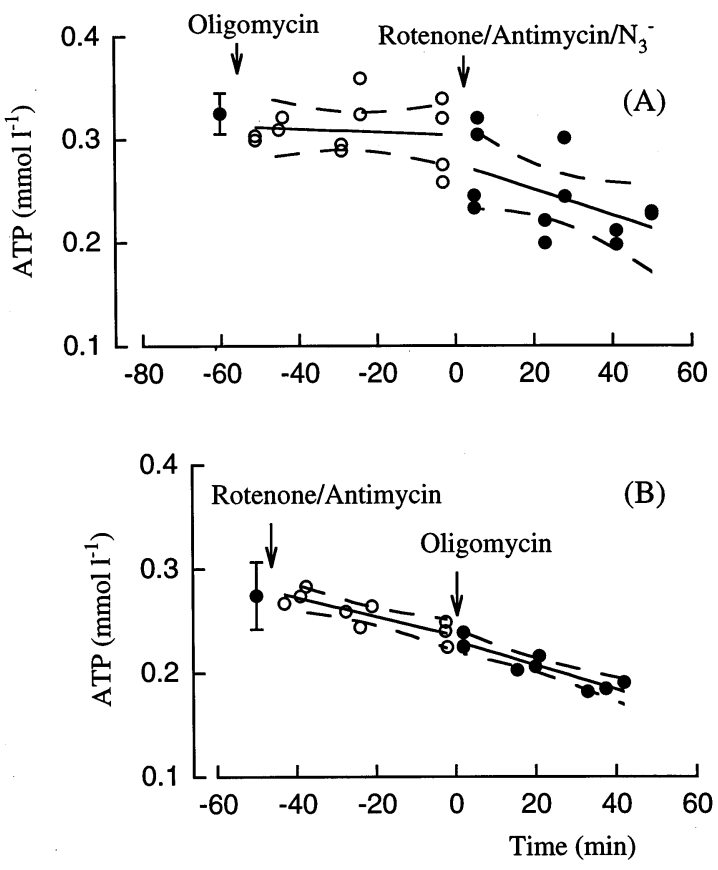

Fig. 2. Maintenance or degradation of ATP accumulated during state III respiration at $3^{\circ} \mathrm{C}$ (A) during exposure to oligomycin, followed by a combined effect of rotenon, antimycin and sodium azide, (B) during exposure to rotenon/antimycin and then oligomycin. Significant ATP degradation depended on the action of rotenon and antimycin leading to the conclusion that reversal of mitochondrial $F_{0} F_{1}$-ATP synthase was not contributing to ATP depletion.

\subsection{Thermal sensitivity of mitochondrial respiration}

State III respiration increased exponentially with rising temperature between 0 and $9^{\circ} \mathrm{C}$, after which no further increase was seen. The difference between respiratory states III and IV + oligomycin also rose exponentially to $9^{\circ} \mathrm{C}$ but declined above this temperature (Fig. 3). This difference is seen as a conservative measure of phosphorylation dependent respiration considering that proton leakage is likely to be smaller under state III than state IV conditions. States IV and IV + respiration continued to rise more or less exponentially within the temperature range investigated. In consequence, the drop in states III-IV + respiration not only reveals a reduction of phosphorylation at temperatures above $9^{\circ} \mathrm{C}$ but also that the continued rise in proton leakage accounts for a larger fraction of mitochondrial respiration.

Arrhenius plots of respiration rates still showed a slight exponential rise for state III respiration in the low temperature range (Fig. 4A) reflected by a significant increase in $Q_{10}$ values and also in Arrhenius activation energies with rising temperature (Fig. 5). The progressive rise in the temperature dependence of state 
III respiration beyond $3^{\circ} \mathrm{C}$ led to a more or less constant RCR value (Fig. 1) until an Arrhenius break temperature (ABT) was reached, visible as a sharp drop in the thermal sensitivity of state III respiration (Fig. 3 ). This indicates loss of protein function with apparent activation energies reaching negative values for the states III-IV + difference. This pattern is also reflected in the modification of overall $Q_{10}$ values which rose between 0 and $9^{\circ} \mathrm{C}$ but dropped sharply beyond $9^{\circ} \mathrm{C}$ (Fig. 5B).

With an average activation energy of $79 \mathrm{~kJ} \mathrm{~mol}^{-1}$ and a $Q_{10}$ value of 4.2 the temperature dependence of state IV + respiration was similar to that of state IV (cf. Fig. 4B). At temperatures above $9{ }^{\circ} \mathrm{C} Q_{10}$ values were much higher for state IV than for state III rates, thereby leading to progressive uncoupling of mitochondria visible as a drop in $\mathrm{RCR}+$ values (state III/state $\mathrm{IV}+$ oligomycin) (Fig. 1A).

Determination of classical and effective $\mathrm{P} / \mathrm{O}$ ratios yielded numbers between 1.5 and 2 for both. Effective $\mathrm{P} / \mathrm{O}$ ratios, which in contrast to classical values were mostly determined at low phosphorylation potential (low $[\mathrm{ATP}] /[\mathrm{ADP}]\left[\mathrm{P}_{\mathrm{i}}\right]$ ratio), fell significantly at high
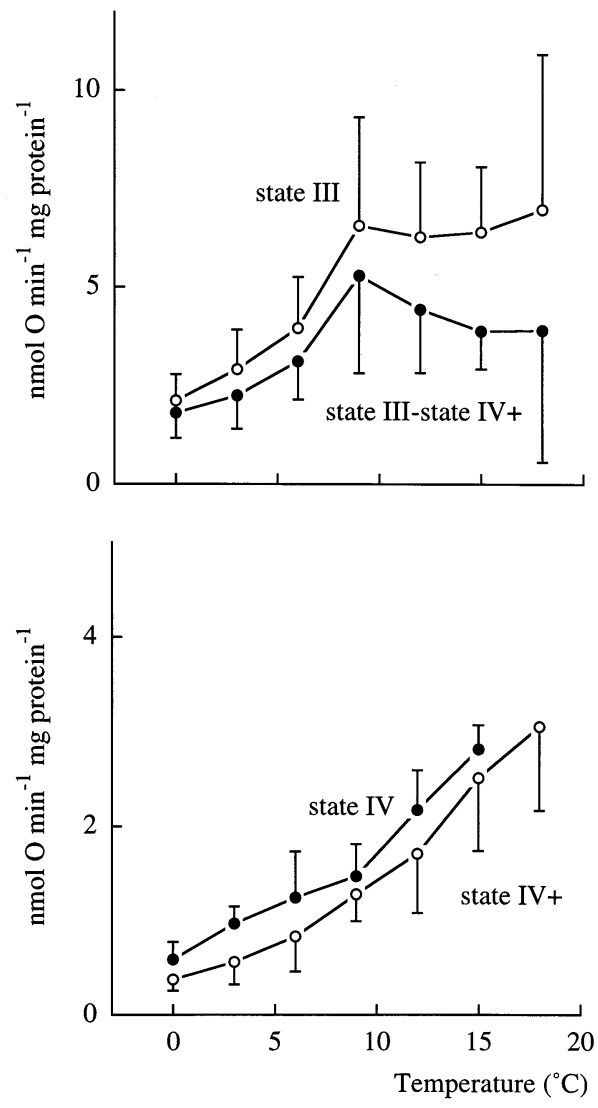

Fig. 3. Temperature dependence of (A) the rates of state III respiration (open symbols) and the difference between the rates of state III and state IV + respiration (closed symbols) and (B) the rates of state IV (closed symbols) and state IV + respiration (open symbols) of gill mitochondria from L. elliptica.
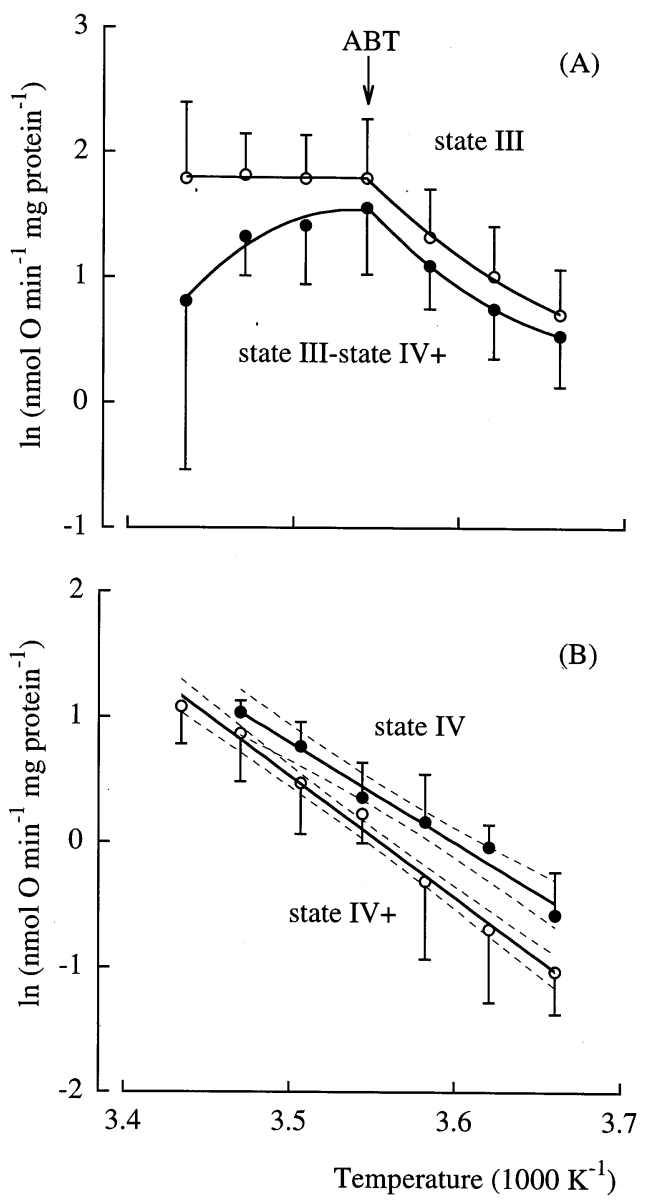

Fig. 4. Arrhenius plots of (A) state III respiration and the difference between the rates of state III and state IV + respiration as well as (B) state IV and state IV + respiration (see Fig. 3). The Arrhenius break temperature (ABT) results as the intersection of linear $(r=0.16$ above $\mathrm{ABT})$ and second order polynomial regressions $(r=1.0$ below ABT) for state III or as the intersection of two second order polynomial regressions for state III-IV $+(r=0.98$ above ABT; $r=1.0$ below ABT). Continuous linear regressions for respiratory states IV $(r=$ $0.99)$ and state IV + oligomycin $(r=1.0)$ mirror the non-existence of significant discontinuities in both states. Dashed lines indicate the $95 \%$ confidence interval.

temperatures (Fig. 6B). The $\mathrm{P}_{\mathrm{O}}$ dependence of the $\mathrm{P} / \mathrm{O}$ ratio appears negligible as indicated by Fig. 5C and excludes a strong influence of an alternative oxidase on the determination of $\mathrm{P} / \mathrm{O}$ ratios [37].

\section{3. $N A D P^{+}$-dependent isocitrate dehydrogenase}

$\mathrm{NADP}^{+}$-dependent isocitrate dehydrogenase was determined in isolated mitochondria and showed a specific activity of $2.39 \pm 1.13 \mathrm{mU} \mathrm{mg}^{-1}$ mitochondrial protein or $22.9 \pm 4.6 \mathrm{mU} \mathrm{g}^{-1}$ fresh mass in gill tissue at $0^{\circ} \mathrm{C}$ and $99.34 \pm 30.20 \mathrm{mU} \mathrm{mg}^{-1}$ mitochondrial protein or $818.1 \pm 98.7 \mathrm{mU} \mathrm{g}^{-1}$ fresh mass at $25^{\circ} \mathrm{C}$. Enzyme activity increased with assay temperature with a mean $Q_{10}$ of 9.9 between 0 and $9^{\circ} \mathrm{C}$, which is significantly higher than the $Q_{10}$ of mitochondrial state III respira- 
tion between 0 and $3^{\circ} \mathrm{C}$ but similar to the mitochondrial values found at higher temperatures (Fig. 5). The Arrhenius plot shows a break at $9^{\circ} \mathrm{C}$ above which enzyme activity increased less steeply with temperature (Fig. 7). The Arrhenius activation energy in the low temperature range, between 0 and $9^{\circ} \mathrm{C}$ was $138.4 \mathrm{~kJ}$ $\mathrm{mol}^{-1}$ and dropped to a value of $67.5 \mathrm{~kJ} \mathrm{~mol}^{-1}$ above $9^{\circ} \mathrm{C}$.

\section{Discussion}

\subsection{Analysis of mitochondrial function}

In a trade-off between the preservation of mitochondrial integrity and the purity of the preparation a low number of centrifugation steps and high level of BSA led to high RCR of the mitochondrial preparations in this and a companion study on Antarctic fish mitochondria [23]. This was considered essential for valid conclu-
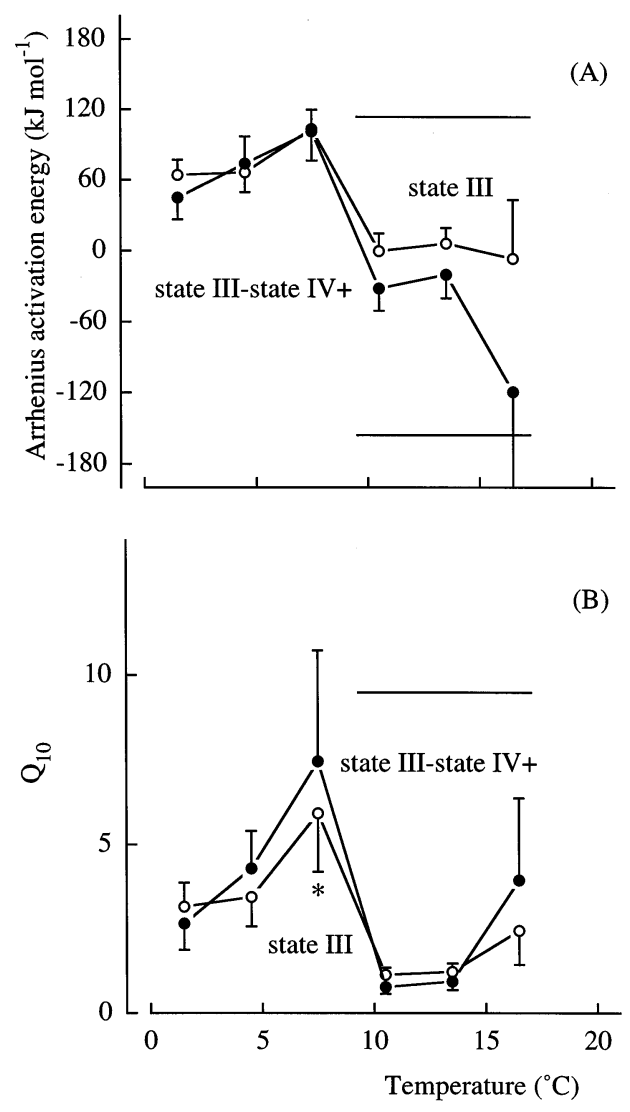

Fig. 5. (A) Arrhenius activation energies and (B) $Q_{10}$ values of state III respiration and the difference between the rates of state III and state IV + respiration for the $3^{\circ} \mathrm{C}$ temperature intervals depicted in Fig. 3. Data (means $\pm \mathrm{SE}$ ) are depicted for the respective mean temperature of the interval. A horizontal line indicates onset and maintenance of a significant difference from means grouped for lower temperatures (valid for both plots in B). *, indicates a significant rise of $Q_{10}$ for state III respiration between 0 and $9^{\circ} \mathrm{C}$.
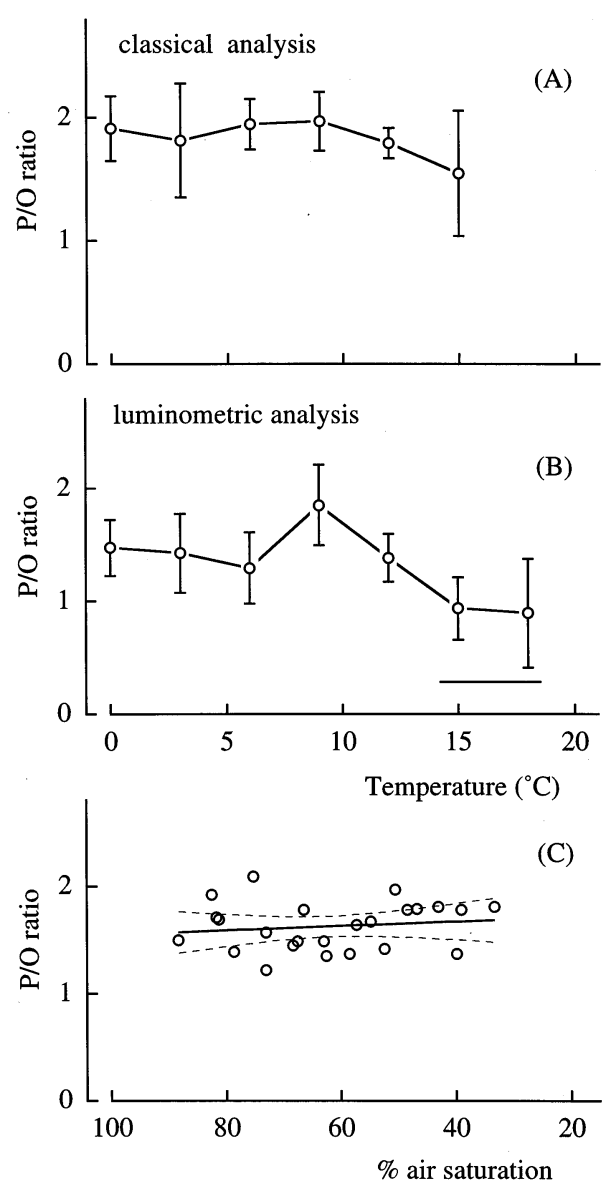

Fig. 6. Dependence of $\mathrm{P} / \mathrm{O}$ ratios in mitochondria from L. elliptica on temperature and oxygen ( $\%$ air saturation) (A) classical $\mathrm{P} / \mathrm{O}$ ratios $=$ based on graphical analysis of the transition between state III and state IV respiration, (B) effective $\mathrm{P} / \mathrm{O}$ ratios = based on luminometric ATP assay and oxygen consumption analyses, (C) $\mathrm{P} / \mathrm{O}$ ratios as a function of oxygen. A horizontal line denotes onset and maintenance of a significant difference from values grouped for lower temperatures. Dashed lines indicate the $95 \%$ confidence interval.

sions concerning the temperature dependencies of state III and proton leakage. ADP generation by adenylate kinase (e.g. [4,30]) might influence state IV and was excluded by the presence of diadenosine pentaphosphate $\left(\mathrm{AP}_{5} \mathrm{~A}\right)$ and the elimination of $\mathrm{Mg}^{2+}$.

Any difference between states IV and IV + oligomycin is suggested to indicate ATP turnover by mitochondrial ATPases [31]. Accordingly, ATP degradation occurred under the effect of oligomycin and even more so during complete inhibition of the respiratory chain (Fig. 2) similar to results obtained in a study on rat liver mitochondria [31]. Mitochondrial $\mathrm{F}_{0} \mathrm{~F}_{1}$-ATPase is not involved in ATP degradation since ATP depletion continued under oligomycin (Fig. 2B). Such ATP hydrolysis is possibly associated with the maintenance of non- $\mathrm{H}^{+}$ion gradients or with structural transitions [31]. The question arises why ATP depletion was less under oligomycin than with rotenone/antimycin/ 
azide. In general, oligomycin allows for substrate oxidation and respiratory activity associated with proton leakage. This includes substrate level phosphorylations in the citric acid cycle. In contrast, the other inhibitors will cut out all respiration and thereby proton leakage and all citric acid cycle activity. Respiration under oligomycin [31] therefore is a valid estimate of metabolism associated with proton leakage. The small rates of spontaneous ATP depletion seen excluded that a large fraction of unspecific ATP turnover and associated oxygen consumption occurred. At maximum phosphorylation potentials $\mathrm{P} / \mathrm{O}$ ratios would be underestimated by $9.5 \pm 2.5 \%$.

Mitochondrial proton leakage covers a significant fraction, namely $25-50 \%$ of SMR in both endo- and, very likely ectothermal organisms [7,9,41]. SMR including proton leakage will depend on aerobic scope (cf. [51]). Proton leakiness rises exponentially in the range of high proton motive force $(\Delta p,[5,9])$ and, therefore, is higher during state IV than state III respiration $[5,17,41]$. Rising ATP/ADP ratios cause $\Delta p$ and thus proton
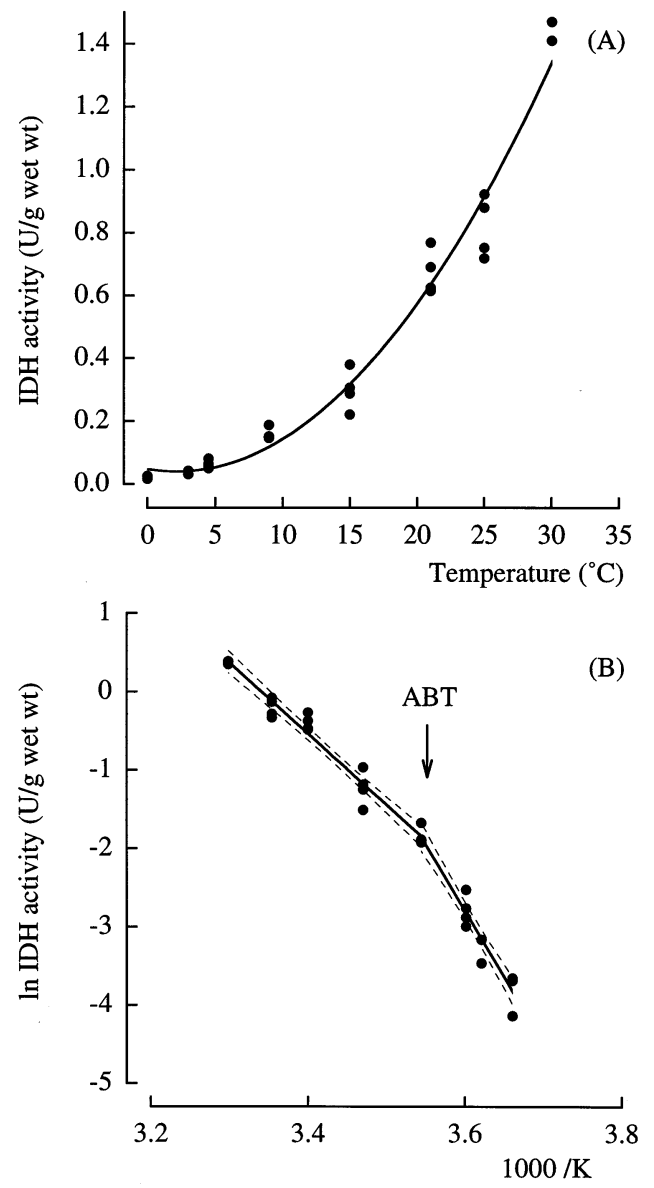

Fig. 7. Temperature dependence of mitochondrial $\mathrm{NADP}^{+}$dependent isocitrate dehydrogenase from L. elliptica gill mitochondria (A). The Arrhenius plot (B) reveals a significant break with the application of two linear regressions $(r=0.97$ below ABT; $r=0.98$ above ABT). Dashed lines indicate the $95 \%$ confidence interval. leakage to increase progressively leading to a decrease in $\mathrm{P} / \mathrm{O}$ ratio (cf. [16]). Finally, state IV respiration will reflect a situation close to the resting cell, with mitochondria idling at minimal phosphorylation activity and constantly high phosphorylation potential.

Oligomycin caused $\Delta p$ to rise in resting rat skeletal muscle by $10 \pm 8 \mathrm{mV}$ from 145 to $155 \mathrm{mV}$ [41] indicating that leakiness might be overestimated in our data compared to the true resting situation. However, we conclude that this deviation was rather small: Oligomycin treatments led to similar state IV + rates regardless of whether it was added at low or high ratios of ATP/ADP. The slope of the rise in proton leakiness with $\Delta p$ is small in most (vertebrate) ectotherms compared to endotherms [9]. Moreover, a potential increase in $\Delta p$ under oligomycin was probably time dependent as indicated by a trend of state IV + respiration to rise, however, only 10-15 min after the addition of oligomycin (not shown in figures). This delay was much shorter in fish mitochondria and may no longer be visible in the more active mammalian mitochondria. In conclusion, the initial rate observed under oligomycin may be close to the true rate of proton leakage in mitochondria of resting cells at maximum phosphorylation potential.

Our analysis of state IV + respiration as a measure of mitochondrial proton leakiness did not include an analysis of membrane potential, however, the change in $\Delta p$ with temperature is small [17], especially since alphastat change in extramitochondrial $\mathrm{pH}$ maintains $\Delta \mathrm{pH}$ (cf. [34]). The continuity and similarity of the thermal responses of respiratory states IV and IV + (Figs. 3 and 4) over a large temperature range confirms that the basic temperature dependence of proton leakiness remains unchanged between state IV and state IV + oligomycin and is not related to drastic changes in membrane or phosphorylation potentials (see below).

\subsection{Mitochondrial capacity and proton leakage}

Aerobic capacity of mitochondria $\left(2.1 \mathrm{nmol} \mathrm{O} \mathrm{min}^{-1}\right.$ and $\mathrm{mg}$ protein at $0^{\circ}$ ) isolated from the gills of Laternula elliptica was in the same order of magnitude as the capacity of other bivalve mitochondria when extrapolated to $0^{\circ} \mathrm{C}$ with a $Q_{10}$ of $2.2-2.5$ [39]. This preliminary comparison does not lead us to expect significant cold compensation in Antarctic bivalve mitochondria, i.e. there is no rise in temperature specific rates above those expected from a normal $Q_{10}$ relationship. Johnston et al. [28,29] and Guderley [22] also concluded that cold compensation of mitochondrial capacity (state III) in fish does not occur. Accordingly, Houlihan and Allan [25] did not find significant cold compensation in the metabolic rate of Antarctic gastropods. Obviously, an upregulation of mitochondrial capacity is not required in stenothermal animals and may be restricted to eurythermal species adapted to cold [39]. 
Proton leakage accounted for respiratory rates of $0.38 \pm 0.12 \mathrm{nmol} \mathrm{O} \mathrm{min}{ }^{-1} \mathrm{mg}^{-1}$ mitochondrial protein

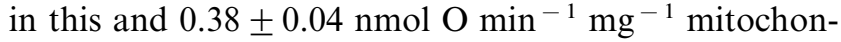
drial protein in our companion study of notothenioid fish (Lepidonotothen nudifrons) liver mitochondria. When proton leakage rates quantified in ectothermal vertebrates [6,9] are extrapolated to low temperatures they are 6-7 times higher in lizard or trout mitochondria at $0^{\circ} \mathrm{C}$ than in mitochondria from the Antarctic species. This supports our earlier hypothesis that proton leakage is down regulated in parallel with SMR in Antarctic ectotherms. Low leakiness may compensate for the increased number of mitochondria in these cold adapted animals $[38,39]$.

\section{3. $\mathrm{P} / \mathrm{O}$ ratios}

Proton leakage in vivo may lead to resting $\mathrm{P} / \mathrm{O}$ ratios even below 1 . This occurs in mammalian tissue [41] and very likely also in tissues of ectotherms at one order of magnitude lower values of SMR and proton leakage. In the assay of mitochondrial respiration the true mechanistic $\mathrm{P} / \mathrm{O}$ ratio will also be underestimated depending on the degree of proton leakage.

Despite analysis at low phosphorylation potential $\mathrm{P} / \mathrm{O}$ ratios in our study $(1.5-2)$ were below those $(2.7-3)$ seen during glutamate respiration in gill mitochondria of oysters (Crassostrea gigas) adapted to $22^{\circ} \mathrm{C}$ [10], in gill mitochondria of ribbed mussel (Modiolus demissus) acclimated to $15^{\circ} \mathrm{C}$ [11] and in heart mitochondria of Atlantic squid (Illex illecebrosus) acclimated to $11^{\circ} \mathrm{C}$ [32]. Following the rationale of Davis and Davis-van Thienen [16] this might indicate elevated proton leakiness during state III respiration in cold adapted mitochondria, especially at higher temperatures. Correction of $\mathrm{P} / \mathrm{O}$ values for proton leakage resulted in somewhat higher values (1.9-2.4). Further investigation needs to address to what extent a change in membrane composition during latitudinal cold adaptation (e.g. [46]) may lead to an increased contribution of proton leakiness to state III respiration.

\subsection{Thermal characteristics of respiratory states}

The Arrhenius activation energies $\left(E_{\mathrm{a}}\right)$ of state III and states III-IV + respiration rates in L. elliptica mitochondria were about twice than expected from an extrapolated correlation of $E_{\mathrm{a}}$ values with temperature in deep sea and temperate marine invertebrate mitochondria between 5 and $40^{\circ} \mathrm{C}$ [15]. This comparison may be problematic since mitochondria in the study by Dahlhoff et al. were mostly uncoupled, a state where respiration rate may exceed state III owing to the drop in intramitochondrial $\mathrm{pH}$ [20]. The value of around 60 $\mathrm{kJ} \mathrm{mol}^{-1}$ found in L. elliptica gill mitochondria between 0 and $3^{\circ} \mathrm{C}$ was similar to the values found in liver mitochondria from Antarctic fish, L. nudifrons $(47.5 \mathrm{~kJ}$ $\mathrm{mol}^{-1}$ [23]) and Trematomus bernacchii $\left(38.3 \mathrm{~kJ} \mathrm{~mol}^{-1}\right.$, measured above $5^{\circ} \mathrm{C}$, [49]), or in red muscle mitochondria from Notothenia coriiceps $\left(73 \mathrm{~kJ} \mathrm{~mol}^{-1}\right.$, calculated from [22] for data between -1.5 and $+2.5^{\circ} \mathrm{C}$ ). Mitochondria from temperate zone fish, short-horned sculpin, Myoxocephalus scorpio exhibited some cold induced decrease in activation energy (from $70.2 \mathrm{~kJ}$ $\mathrm{mol}^{-1}$ in fish acclimated to $15^{\circ} \mathrm{C}$ to $55.4 \mathrm{~kJ} \mathrm{~mol}^{-1}$ in fish acclimated to $5^{\circ} \mathrm{C}$; [21]). These comparisons might indicate that $E_{\mathrm{a}}$ of state III respiration is largely unaffected by polar cold adaptation, whereas seasonal cold adaptation may still have an effect. Overall, $Q_{10}$ or $E_{\text {a }}$ values for state III respiration in L. elliptica mitochondria at low temperature $\left(0-3^{\circ} \mathrm{C}\right)$ were not exceptionally different from those reported for other species and there appears to be no clear trend with respect to temperature adaptation [39].

Owing to the progressive rise in $E_{\mathrm{a}}$ of state III respiration the uncoupling of mitochondria becomes significant only beyond $\mathrm{ABT}\left(9^{\circ} \mathrm{C}\right)$. A high degree of uncoupling is supported by the continuous increase in proton leakage (state IV + ), with constant $E_{\text {a }}$ and no ABT. The ABT of state III was much lower in $L$. elliptica than in our companion study on notothenioid fish liver mitochondria where an ABT was not seen below $18^{\circ} \mathrm{C}$. In the fish the $E_{\mathrm{a}}$ of $\mathrm{H}^{+}$leakage was always higher than $E_{\mathrm{a}}$ of state III leading to an early progressive uncoupling of mitochondria with rising temperature [23].

The finding of a rather high $Q_{10}$ (4.2) for states IV and IV + respiration in an Antarctic bivalve and a fish suggests that the thermal sensitivity of $\mathrm{H}^{+}$leakage is especially high in polar stenotherms compared to other ecto- and endotherms where $Q_{10}$ ranges between 1.3 and 2.1 [39]. Only recently, Brand et al., demonstrated a correlation between phospholipid composition (long chain polyunsaturates) and proton leak. This effect is not direct but presumably through an interaction between membrane bound proteins and the lipids since leakage of protein-free mitochondrial membrane vesicles was only $5 \%$ of the value found in intact mitochondria. The nature of that protein is still obscure $[8,9]$. Whereas $E_{\mathrm{a}}$ of $\mathrm{H}^{+}$leakage appears to rise during cold adaptation the thermal sensitivity of passive $\mathrm{Na}^{+}$flux in mitochondrial membrane vesicles from cold adapted rainbow trout is reduced [52]. The conclusion arises that proton leakage should involve an enzyme catalyzed process rather than simple diffusion of protons (which should be indicated by a $Q_{10}$ significantly below 2 [19]). These observations led us to hypothesize that a mitochondrial substrate cycle involving transhydrogenase and NADP dependent IDH [42] may be responsible for at least a fraction of the proton leak [39]. 


\subsection{NADP dependent isocitrate dehydrogenase (IDH)}

In this context it is intriguing that high $E_{\mathrm{a}}$ and $Q_{10}$ values of $\mathrm{H}^{+}$leakage and IDH (NADP) go hand in hand. Functional relevance of cold adapted NADP-dependent IDH is strongly suggested by a clear inverse correlation between mean habitat temperature and predominance of a mitochondrial isoenzyme with high $E_{\mathrm{a}}$ values in cold adapted lugworms, Arenicola marina $[27,39]$. In general, $E_{\mathrm{a}}$ values of NADP dependent IDH from cold adapted animals in a latitudinal gradient are higher than in temperate zone species or populations and especially high in stenothermal versus eurythermal species [39]. Forward and backward reaction of IDH (NADP) exhibit identical thermal sensitivities (Pörtner and Hirse, unpublished).

$E_{\text {a }}$ of state III respiration and mitochondrial phosphorylating respiration (states III-IV + ) at elevated temperatures below ABT approached the one evaluated for IDH $\left(138 \mathrm{~kJ} \mathrm{~mol}^{-1}\right)$. Interpretation of these findings must remain speculative at present. It might suggest that the control of state III respiration shifted towards control by IDH (NADP) and proton leakage via transhydrogenase. According to a suggested model isocitrate is cycled between NAD as well as NADP dependent IDH [26,42]. Transhydrogenase reduces $\mathrm{NADP}^{+}$at the expense of NADH and the mitochondrial proton gradient:

\section{IDH (NAD):}

isocitrate $^{3-}+\mathrm{NAD}^{+}$

$\rightarrow$ 2-oxoglutarate ${ }^{2-}+\mathrm{NADH}+\mathrm{CO}_{2}$

IDH (NADP):

2-oxoglutarate ${ }^{2-}+\mathrm{NADPH}+\mathrm{CO}_{2}$

$\rightarrow$ isocitrate $^{3-}+\mathrm{NADP}^{+}$

Transhydrogenase:

$\mathrm{NADH}+\mathrm{NADP}^{+}+\mathrm{H}_{\text {(out) }}^{+}$

$\rightarrow \mathrm{NAD}^{+}+\mathrm{NADPH}+\mathrm{H}_{\text {(in) }}^{+}$

IDH (NADP) may adopt a significant role in determining the flux through this futile substrate cycle which not only enhances the sensitivity of the TCA cycle to changes in energy demand but should comprise a significant fraction of respiration and the mitochondrial proton leak, especially under resting conditions. The similarity of the proton leak and the transhydrogenase cycle with respect to their dependence on proton motive force of the inner mitochondrial membrane supports this conclusion [39].

High $E_{\mathrm{a}}$ levels of $\mathrm{H}^{+}$leakage and IDH in cold adapted species are unexpected in the light of the long held general paradigm that $E_{\mathrm{a}}$ is reduced in cold adapted species to facilitate metabolic flux. However, enzymes with a low activity, some of which are flux limiting, have hardly been considered and this may be the reason why such a rise in $E_{\mathrm{a}}$ has been overlooked, for example in glyceraldehydephosphate dehydrogenase, phosphofructokinase, IDH [39]. Diffusional limitations in the cold [43] may require a certain amount of enzyme molecules for the maintenance of metabolic flux. A rise in activation energy as seen in IDH would allow for reduced substrate flux at maintained or elevated enzyme levels. Such a rise in $E_{\mathrm{a}}$ in some enzymes would actually support metabolic depression in polar species below the rate otherwise expected from the effect of mitochondrial proliferation [39].

\subsection{Critical and Arrhenius break temperatures}

ABTs of mitochondrial phosphorylation and IDH were identical. In conclusion, the ABT of mitochondrial phosphorylation possibly involves the progressive heat inactivation of mitochondrial proteins such as IDH. O'Brien et al. [36] demonstrated that heat inactivation of membrane bound succinate dehydrogenase and the matrix enzyme malate dehydrogenase set in at about the same temperature (when cytochrome oxidase showed a transient activation). Accordingly, the fate of individual mitochondrial enzymes as well as a change in membrane properties may delineate the change in thermal properties of mitochondrial function.

Although the ABTs of mitochondrial state III respiration and IDH are the lowest so far described in a marine ectotherm they are still above the $T_{\mathrm{c}}$ of Laternula elliptica which, according to changes in the levels of anaerobic mitochondrial metabolites, is found between 3 and $6{ }^{\circ} \mathrm{C}$ (Pörtner et al., unpublished). In a recent comparative overview of Arrhenius break temperatures in mitochondria from various fish and invertebrate species the ABT of uncoupled respiration varied depending on adaptation temperature, however, at values above the maximum habitat temperature [49] and also above the critical temperature of the whole animal [39]. The difference between ABT and maximum habitat temperature appeared to rise at lower temperatures, from an average of $15^{\circ}$ to a value of $25^{\circ}$ in the temperature range between 25 and $5^{\circ} \mathrm{C}$. The data point from $T$. bernacchii mitochondria, however, did not fit this general pattern but the difference between ABT and habitat temperature was less (about $18^{\circ}$ ) than expected from the correlation [49]. In L. elliptica an even smaller difference of about $7-9^{\circ} \mathrm{C}$ results between habitat temperature and ABT and of only $3-6^{\circ} \mathrm{C}$ between critical temperature and ABT. Further comparison of invertebrate and vertebrate mitochondria is needed for an understanding of these differences in thermal properties. 


\section{Conclusions}

It may be a general principle, that the $\mathrm{ABT}$ of mitochondrial function is found above the $T_{\mathrm{c}}$ of the whole animal in invertebrates and fish. Therefore, mitochondrial dysfunction possibly reflected in the ABTs of mitochondrial respiration or IDH activity is unlikely to be responsible for setting the upper limit of thermal tolerance and for eliciting the transition to anaerobiosis at the $T_{\mathrm{c}}$. In the bivalve L. elliptica, the only Antarctic invertebrate so far investigated, the ABTs of isocitrate dehydrogenase and state III respiration were identical and found only slightly above the $T_{\mathrm{c}}$ of these animals (this study). In fish ABTs of mitochondrial functions are considerably higher than the $T_{\mathrm{c}}$ [49].

The following scenario likely explains the upper limits of thermal tolerance [39]: Mitochondria of Antarctic invertebrates and fish have in common a large thermal sensitivity of proton leakage and NADP dependent IDH. Elevated temperatures cause a large and early rise in oxygen demand (e.g. [47]) which may be due to proton leakage and not associated with an equivalent rise in ATP turnover [39]. At the $T_{\mathrm{c}}$ this oxygen demand can no longer be covered by oxygen delivery through ventilation and circulation [38]. Moreover, the limited amount of oxygen available at higher temperatures is inefficiently used by mitochondria. These processes will lead to the early development of a pronounced energy deficit and anaerobiosis [39].

\section{Acknowledgements}

We are indebted to A. Chapman, R. Wood and S. Dunkerley for the supply of clams and numerous extra dives. The patient technical support by $\mathrm{S}$. Leighton during various centrifuge breakdowns is gratefully remembered. We also like to thank A. Clarke for reading and commenting on the manuscript. Alfred-WegenerInstitute Publication No. 1671.

\section{References}

[1] Alp PR, Newsholme EA, Zammit VA. Activities of citrate synthase and $\mathrm{NAD}^{+}$-linked and $\mathrm{NADP}^{+}$-linked isocitrate dehydrogenase in muscle from vertebrates and invertebrates. Biochem J 1976;154:689-700.

[2] Arntz WE, Brey T, Gallardo VA. Antarctic Zoobenthos. Oceanogr Mar Biol: Ann Rev 1994;32:241-304.

[3] Ballantyne JS, Moyes CD. The effects of salinity acclimation on the osmotic properties of mitochondria from the gill of Crassostrea gigas. J Exp Biol 1987;133:449-56.

[4] Blier PU, Guderley H. Mitochondrial activity in rainbow trout red muscle: the effect of temperature on the ADP-dependence of ATP synthesis. J Exp Biol 1993;176:145-57.

[5] Brand MD. The contribution of the leak of protons across the mitochondrial inner membrane to standard metabolic rate. J Theor Biol 1990;145:267-86.
[6] Brand MD, Couture P, Else PL, Withers KW, Hulbert AJ. Evolution of energy metabolism. Proton permeability of the inner membrane of liver mitochondria is greater in a mammal than in a reptile. Biochem J 1991;275:81-6.

[7] Brand MD, Chien L-F, Ainscow EK, Rolfe DFS, Porter RK. The causes and functions of mitochondrial proton leak. Biochim Biophys Acta 1994;1187:132-9.

[8] Brookes PS, Rolfe DFS, Brand MD. The proton permeability of liposomes made from mitochondrial inner membrane phospholipids: comparison with intact mitochondria. J Membr Biol 1997; 155:167-73.

[9] Brookes PS, Buckingham JA, Tenreiro AM, Hulbert AJ, Brand MD. The proton permeability of the inner membrane of liver mitochondria from ectothermic and endothermic vertebrates and from obese rats: correlations with standard metabolic rate and phospholipid fatty acid composition. Comp Biochem Physiol 1998;119B:325-34.

[10] Burcham JM, Paynter KT, Bishop SH. Coupled mitochondria from oyster gill tissue. Mar Biol Lett 1983;4:349-56.

[11] Burcham JM, Ritchie AL, Bishop SH. Preparation and some respiratory properties of coupled mitochondria from ribbed mussel (Modiolus demissus) gill tissue. J Exp Zool 1984;229:55-67.

[12] Chance B, Williams GR. The respiratory chain and oxidative phosphorylation. Adv Enzymol 1956;17:65-134.

[13] Clarke A. Temperature and energetics: an introduction to cold ocean physiology. In: Pörtner HO, Playle R, editors. Cold Ocean Physiology. Cambridge University Press, 1998:3-30.

[14] Crockett EL, Sidell BD. Some pathways of energy metabolism are cold adapted in Antarctic fishes. Physiol Zool 1990;63:47288.

[15] Dahlhoff E, O'Brien J, Somero GN, Vetter RD. Temperature effects on mitochondria from hydrothermal vent invertebrates: evidence for adaptation to elevated and variable habitat temperatures. Physiol Zool 1991;64:1490-518.

[16] Davis EJ, Davis-van Thienen WIA. An assessment of the role of proton leaks in the mechanistic stoichiometry of oxidative phosphorylation. Arch Biochem Biophys 1991;289:184-6.

[17] Dufour S, Rousse N, Canioni P, Diolez P. Top-down control analysis of temperature effect on oxidative phosphorylation. Biochem J 1996;314:743-51.

[18] Dunn JF. Low-temperature adaptation of oxidative energy production in cold-water fishes. Can J Zool 1988;66:1098-104.

[19] J.C. Ellory, A.C. Hall, Temperature effects on red cell membrane transport processes, in: K. Bowler, B.J. Fuller (Eds.), Temperature and Animal Cells. Symp. Soc. Exp. Biol., Vol. 31, pp. $53-66$.

[20] Greenbaum NL, Wilson DF. Role of intramitochondrial $\mathrm{pH}$ in the energetics and regulation of mitochondrial oxidative phosphorylation. Biochim Biophys Acta 1991;1058:11-120.

[21] Guderley H, Johnston IA. Plasticity of fish muscle mitochondria with thermal acclimation. J Exp Biol 1996;199:1311-7.

[22] Guderley H. Temperature and growth rates as modulators of the metabolic capacities of fish muscle. In: Pörtner HO, Playle R, editors. Cold Ocean Physiology. Cambridge University Press, 1998:58-87.

[23] Hardewig I, Peck LS, Pörtner HO. Thermal sensitivity of mitochondrial function in the Antarctic Notothenioid Lepidonotothen nudifrons. J. Comp. Physiol. B. 1999 (in press).

[24] Hardy P. Biomass estimates from shallow water infaunal communities at Signy Island, South Orkney Islands. Br Antarctic Survey Bull 1972;31:93-106.

[25] Houlihan DF, Allan D. Oxygen consumption of some Antarctic and British gastropods: an evaluation of cold adaptation. Comp Biochem Physiol 1982;73A:383-7.

[26] Howlett RA, Willis WT. Fiber-type-related differences in the enzymes of a proposed substrate cycle. Biochim Biophys Acta 1998;1363:224-30. 
[27] Hummel H, Sommer A, Bogaards RH, Pörtner HO. Variation in genetic traits of the lugworm Arenicola marina: temperature related expression of mitochondrial allozymes? Mar Ecol Prog Ser 1997;159:189-95.

[28] Johnston IA, Guderley H, Franklin CE, Crockford T, Kamunde C. Are mitochondria subject to evolutionary temperature adaptations? J Exp Biol 1994;195:293-306.

[29] Johnston IA, Calvo J, Guderley H, Fernandez D, Palmer L. Latitudinal variation in the abundance and oxidative capacities of muscle mitochondria in perciform fishes. $\mathbf{J}$ Exp Biol 1998;201:1-12.

[30] Lee CP, Gu Q, Xiong Y, Michell RA, Ernster L. P/O ratios reassessed: mitochondrial $\mathrm{P} / \mathrm{O}$ ratios consistently exceed 1.5 with succinate and 2.5 with NAD-linked substrates. FASEB J 1996;10:345-50.

[31] Masini A, Ceccarelli-Stanzani D, Muscatello U. Phosphorylating efficiency of isolated rat liver mitochondria respiring under the conditions of steady-state 4. Biochim Biophys Acta 1983;724:251-7.

[32] Mommsen TP, Hochachka PW. Respiratory and enzymatic properties of squid heart mitochondria. Eur J Biochem 1981;120:345-50.

[33] Moyes CD, Moon TW, Ballantyne JS. Glutamate metabolism in mitochondria from Mya arenaria mantle: effects of $\mathrm{pH}$ on the role of glutamate dehydrogenase. J Exp Zool 1985;236:293301.

[34] Moyes CD, Buck LT, Hochachka PW. Temperature effects on $\mathrm{pH}$ of mitochondria isolated from carp red muscle. Am J Physiol 1988;254:R611-5.

[35] Nickerson DM, Facey DE, Grossman GD. Estimating physiological thresholds with continuous two-phase regression. Physiol Zool 1989;62:866-87.

[36] O'Brien J, Dahlhoff E, Somero G. Thermal resistance of mitochondrial respiration: hydrophobic interactions of membrane proteins may limit thermal resistance. Physiol Zool 1991;64:1509-26.

[37] Pörtner HO, Grieshaber MK. Critical $\mathrm{P}_{\mathrm{O}_{2}}$ (s) in oxyconforming and oxyregulating animals: gas exchange, metabolic rate and the mode of energy production. In: Bicudo JEPW, editor. The Vertebrate Gas Transport Cascade: Adaptations to Environment and Mode of Life. Boca Raton, FL: CRC Press, 1993:33057.

[38] Pörtner HO, Hardewig I, Sartoris FJ, van Dijk P. Energetic aspects of cold adaptation: critical temperatures in metabolic, ionic and acid-base regulation? In: Pörtner HO, Playle R, editors. Cold Ocean Physiology. Cambridge University Press, 1998:88-120.

[39] Pörtner HO, van Dijk PLM, Hardewig I, Sommer A. Levels of metabolic cold adaptation: trade-offs in eurythermal and stenothermal ectotherms. In: Davison W, Williams $\mathrm{CH}$, editors.
Antarctic Ecosystems: Models for Wider Ecological Understanding. Christchurch, New Zealand: Caxton Press, 1999 (in press).

[40] Ralph R, Maxwell JGH. Growth of two Antarctic lamellibranchs: Adamussium colbecki and Laternula elliptica. Mar Biol 1977;42:171-5.

[41] Rolfe DFS, Brand MD. Contribution of mitochondrial proton leak to skeletal muscle respiration and to standard metabolic rate. Am J Physiol 1996;271:C1380-9.

[42] Sazanov LA, Jackson JB. Proton-translocating transhydrogenase and NAD- and NADP-linked isocitrate dehydrogenases operate in a substrate cycle which contributes to fine regulation of the tricarboxylic acid cycle activity in mitochondria. FEBS Lett 1994;344:109-16.

[43] Sidell BD, Hazel JR. Temperature effects the diffusion of small molecules through cytosol of fish muscle. J Exp Biol 1987; 129:191-203.

[44] Sommer A, Klein B, Pšrtner HO. Temperature induced anaerobiosis in two populations of the polychaete worm Arenicola marina. J Comp Physiol 1997;167B:25-35.

[45] Sommer A, Pörtner HO. Exposure of Arenicola marina (L.) to extreme temperatures: adaptive flexibility of a boreal and a subpolar population. Mar Ecol Prog Ser 1999;181:215-26.

[46] Storelli C, Acierno R, Maffia M. Membrane lipids and protein adaptations in Antarctic fish. In: Pörtner HO, Playle R, editors. Cold Ocean Physiology. Cambridge University Press, 1998:16689.

[47] P.L.M. van Dijk, C. Tesch, I. Hardewig, H.O. Pörtner, Physiological disturbances at critically high temperatures. A comparison between stenothermal Antarctic, and eurythermal temperate eelpouts (Zoarcidae), J. Exp. Biol. 1999 (in press).

[48] Yeager DP, Ultsch GR. Physiological regulation and conformation: a BASIC program for the determination of critical points. Physiol Zool 1989;62:888-907.

[49] Weinstein RB, Somero GN. Effects of temperature on mitochondrial function in the Antarctic fish Trematomus bernachii. J Comp Physiol 1998;168:190-6.

[50] Wibom R, Lundin A, Hultman E. A sensitive method for measuring ATP-formation in rat muscle mitochondria. Scand $\mathbf{J}$ Clin Invest 1990;50:143-52.

[51] Wieser W. Developmental and metabolic constraints of the scope of activity in young rainbow trout (Salmo gairdneri). J Exp Biol 1985;118:133-42.

[52] Williams EE, Hazel JR. Thermal adaptation in fish membranes: temporal resolution of adaptive mechanisms. In: Cossins AR, editor. Temperature Adaptation of Biological Membranes. London: Portland Press, 1994:91-106.

[53] Zielinski S, Pörtner HO. Energy metabolism and ATP free-energy change of the intertidal worm Sipunculus nudus below a critical temperature. J Comp Physiol 1996;166B:492-500. 